\title{
Premenstrual Syndrome and Spousal Social Support among Women in Isfahan City (Iran)
}

\author{
Hajar Rezaee ${ }^{1}$, Maryam Amidi Mazaheri ${ }^{1} \&$ Fatemeh Sadrhashemi ${ }^{1}$ \\ ${ }^{1}$ School of Health, Isfahan University of Medical Sciences, Isfahan, Iran \\ Correspondence: Maryam Amidi Mazaheri, Department of Health Services, School of Health, Isfahan University \\ of Medical Sciences, Isfahan, Iran. E-mail: maryamamidi@hlth.mui.ac.ir
}

Received: June 12, 2016 Accepted: August 3, 2016 Online Published: August 25, 2016

doi:10.5539/gjhs.v9n4p233 URL: http://dx.doi.org/10.5539/gjhs.v9n4p233

\begin{abstract}
Premenstrual Syndrome (PMS) is one of the most common disorders in women known to cause impairment of daily function and relationships with others. This study was down to investigate the premenstrual syndrome, physical activity and spousal social support status among women in Isfahan city. This descriptive-analytical study was down in health centers of Isfahan city in Iran 2015. The study populations were 190 couples in reproductive age; symptoms of premenstrual syndrome and spousal social support information were collected by self-report questionnaires. American College of Obstetricians and Gynecologists (ACOG) criteria were used to diagnose PMS. Data were analyzed by SPSS20. According to the data $79.5 \%$ of women were diagnosed with premenstrual syndrome. Desirable spousal social support in premenstrual and during the period were obtained in $12.6 \%$ and $16.3 \%$ respectively. Considering the large number of women suffering from PMS and unfavorable situation of spousal social support, holding educational programs for women and men to deal better with this issue are recommended.
\end{abstract}

Keywords: premenstrual syndrome, spousal social support, Isfahan

\section{Introduction}

\subsection{Introduce the Problem}

To be able to change hygiene and health as one of the human unchallengeable rights to a social value and a kind of long-term useful investment, we should understand the meaning of health and health issues and identify the real health needs and health priorities. One of the most important health issues among female population is the occurrence of the problems related to menstruation including premenstrual syndrome (PMS) (Freeman et al., 2011). PMS is a syndrome which contains of physical and behavioral symptoms going on in the second half of the menstrual cycle and a large number of women around the world suffer from this syndrome. PMS is a sourse of conflict in the women life quality, in the family and social relationships, and in the daily routine living actions (Rezaee, Mahamed, \& Mazaheri, 2015). This problem appears during luteal phase, 7 to 10 days before menstruation, and disappears when bleeding starts (Chantler, Mitchell, \& Fuller, 2009). Based on diagnostic criteria of American College Of Obstetricians and Gynecologists (ACOG) it is necessary to have at least one affective symptom (depression, anxiety, excitability, confusion, disgust anger, isolation) and one physical symptom (breast tenderness, flatus, headache, swollen hands and legs) which occur moderately or severely before menstruation (Bakhshani, 2012). Many specialists know this syndrome as multifactorial disorder and state many reasons for it therefore nomeros and numerous kind of actions are suggested to cop with PMS such as medical, psychiatric, and cognitive treatment (Weisz \& Knaapen, 2009). Social support is one of the factors whitch are important to cop with PMS. Social support is defined as the amount of receiving kindness, the companionship and attention of family, friends, and other people. Social support plays a significant role in people's stress and decreasing the negative effects of high levels of stress whose source is the environment and society. This factor affects directly on life quality and decreases one's vulnerability to stress, depression, and different kinds of mental and physical diseases (Haywood, Slade, \& King, 2007). Spousal support is one of the best forms of of social support for women. Some studies have proven that spouse's supportive behaviors increase can decrease premenstrual syndrome signs in their wives (Rezaee et al., 2015). 


\subsection{Explore Importance of the Problem}

This syndrome involves masses of women and has been known as one of the most important disorders in women (Shin, Ha, Park, \& Heitkemper, 2009). Premenstrual syndrome not only does affect women but also their families. Previous studies indicated that there are a significant positive correlation between premenstrual syndrome and serios psychologic deseases such as postpartum depression, and sadness (Mazaheri et al., 2014). Farthermore, it causes changes in women's behavior like incompatibility with their spouses and misbehavior to wards their children (Kiyani Asyabar, Heidari, Mohammadi Tabar, \& Faghihzadeh, 2009).

Therefore women should be supported during this period by their spouses. Recently the participation of men in matters relating to women's health is taken into consideration in Iran (Najafi-Sharjabad, Hejar Abdul Rahman, \& Yahya, 2014).

\subsection{Describe Relevant Scholarship}

Different studies have shown that about $20 \%$ to $40 \%$ of women have considerable problems with their menstruation during their reproductive ages (Azimi \& Sadeghi, 2013). In Balaha's study conducted on medical students, $45 \%$ reported mild symptoms, $32.6 \%$ moderate symptoms, and $22.4 \%$ severe symptoms (Balaha, Amr, Moghannum, \& Muhaida, 2010). The occurrence of PMS in Iran in Samadi study was apprised as Sixty-two and four-tenths percent (Samadi, Taghian, \& Valiani, 2013).

According to the previous study this syndrome seriously affects couples life, predominantly in couple communication aspect. In the premenstrual time, the arguments and fights between partners contracted, also the severity of it was related with the severity of PMS signs experiment by ladies (Hoga, Vulcano, Miranda, \& Manganiello, 2010).

Furthermore some studies have shown that men are eager and welcome involvement in reproductive health programs and want to support their wives properly (Greene et al., 2006).

Although premenstrual syndrome has been known as one of the most common disorders in the world, its real prevalence cannot be found out easily and the main reason is the broad differences in its definition and diagnostic criteria. The results of the studies on premenstrual syndrome prevalence in the countries under study show that France has the lowest prevalence by $12 \%$ and Iran has the highest prevalence by $98.2 \%$ (Direkvand-Moghadam, Sayehmiri, Delpisheh, \& Sattar, 2014). To explain this huge difference besides wide-ranging dissimilarities in PMS definition and diagnostic criteria another point should be noted, Iran is currently in transition and numerous economical, cultural, social and epidemiological changes are taking place in transition period, like any other developing country Iranian women are faced with numerous problems such as social role pressure and social role conflict wich may increase the risk of PMS in women.

Despite the importance of spousal social support in decline of PMS symptoms, few studies have been done in this area in Iran.

Considering inadequate researches into this field and high occurrence of premenstrual syndrome in reproductive age's women and men's inadequate awareness of this matter and the effects of the syndrome on women health, the aim of this study was to investigate the premenstrual syndrome and spousal social support status among women in Isfahan city.

\section{Method}

\subsection{Identify the Study and Participants}

This study is descriptive-analytic and it was done on 15-45 years old married women in Isfahan selected by simple random sampling method in 2015.

The inclusion criteria were being 20-45 years old, living with spouse, having regular menstruation with 21-35 day cycles lasting 3-10 days, and readiness to participate in the study. Exclusion criteria were having physical diseases, taking medications like contraceptive pills, history of diagnosed psychological diseases such as depression and taking spetial drugs in recent months such as hormone medications, supplements, and compounds, smoking and severe stress such as death of close families or surgical procedure in recent 3 months.

\subsection{Sampling Procedures}

After take the necessary measures and cooperate with the Research Faculty Vice-chancellor and Isfahan's Health Care System, among the total health centers in Isfahan 10 centers were randomly selected. Then through family numbers available in each center 20 families were randomly selected. Health file of selected familis were examine for inclusion and exclusion criteri. Among eligible family file 200 families were selected as selective 
samples in Isfahan. Response rate of the sample was .95. The researchers introduce themselve and give required information about the study to the selected persens and requeste them to volunteer to participate in the study.

From a population of 200 families, 190 individuals volunteered to participate. The pack contains of questionnaires and written consent was given to the participants and asks them to complete it.

\subsection{Measurments}

Data related to PMS was registered by PSA (Premenstrual syndrome assessment). PSA, as a valid scale, has been designed by Delara and colleagues in Iranian culture contex and its reliability and validity have been approved (Delara et al., 2013). This scale contains double units related to premenopausal syndrome: the first unit assesses individual variables and the second unit has thirty two items and assesses signs related to physical aspect (14 items) and symptoms related to mental-behavioral aspect (18 items).

Item scoreing rang is among 3 to 0 (3: severe, 2: moderate, 1 : slight, 0 : asymptomatic). ACOG criteria were used to diagnose PMS. Spousal support were explored by researcher made questionnaire, and its validity was assessed by panel of experts, the initial copy of questionnaire was sent to seven expert of health education and midwifery and its preliminary validity was examined and they were requested to offer their remarks on the items, their commentaries Were imposed to the scale. To examine the reliability of scale, corected scale was present to twenty women. The coefficient of alpha Cranach's was 0.86 . Final version of scale had 14 substances out of which 7 substances were related to the menstrual time and 7 items were related to the time before menstruation. The items scoreing range was 0 to 3 ( 0 : no, not at all; 1: yes, sometimes; 2: yes, often; 3: yes, always).

\section{Results}

The mean and the standard deviation of age of the females under study were $29.92 \pm 5.52$ in the range of 17-45. The mean and the standard deviation of age of the males under study were 34.95 \pm 6.2 in the range of 23-57.

Majority of women were housewives (84.2\%). Only $1.6 \%$ of women were illiterate, $8.4 \%$ had elementary degree, $17.4 \%$ lower secondary degree, $47.4 \%$ high school diploma, $7.9 \%$ associate degree, and $17.4 \%$ had bachelor degree and higher. $1.1 \%$ of men were illiterate, $14.2 \%$ had elementary degree, $27.9 \%$ lower secondary degree, $42.1 \%$ high school diploma, $4.2 \%$ associate degree, and $10.5 \%$ had bachelor degree and higher.

Regarding the intervals between two menstruation cycles, $26.3 \%$ of participants had cycles less than 20 days, $72.6 \%$ had 21-35 day cycles and $1.1 \%$ had cycle intervals with more than 35 days.

Based on ACOG, $79.5 \%$ of women under study had premenstrual syndrome.

The information on PMS physical and emotional symptoms has been presented in table (1), on social support in Table 2.

\subsection{Data Analysis}

The informations were analyzed by SPSS20 statistical software. T-Test, Anova, and Spearman correlation coefficient were used as well.

Table 1. Absolute and relative frequency distribution of premenstrual syndrome symptoms based on physical and emotional dimensions amiong women under study $(\mathrm{n}=190)$

\begin{tabular}{llll}
\hline Space & Symptom & Number & Percent \\
\hline & Abdominal Pain & 111 & 58.4 \\
& Fatigue & 101 & 53.2 \\
& Lethargy And Weakness & 84 & 46.2 \\
& Loss Of Energy & 83 & 43.7 \\
& Breast Tenderness & 76 & 40 \\
Physical & Headache & 76 & 40 \\
& Muscle Pain & 75 & 39.5 \\
& Swollen Breasts & 74 & 38.9 \\
& Flatus & 73 & 38.4 \\
& Changes In Appetite & 59 & 31.1 \\
& Gaining Weight & 42 & 22.1 \\
& Excessive Eating & 32 & 16.8 \\
\hline
\end{tabular}




\begin{tabular}{lll}
\hline Desire For Certain Foods & 29 & 15.3 \\
Swollen Hands And Legs & 26 & 13.7 \\
Irritability & 84 & 44.2 \\
Mood Changes & 82 & 43.2 \\
Feeling Restless & 79 & 31.6 \\
Anxiety & 70 & 36.8 \\
Anger & 68 & 33.2 \\
Restlessness & 63 & 31.6 \\
Sleeping Too Much & 31.6 \\
Nervousness & 60 & 30.5 \\
Boredom & 60 & 23 \\
Reduced Tolerance & 58 & 28.4 \\
Fight & 57 & 27.9 \\
Depression & 54 & 27.9 \\
Seclusion & 53 & 27.4 \\
Uncontrolled Behavior & 53 & 23.2 \\
Losing Hope & 52 & 22.6 \\
Lack Of Concentration & 44 & 20.5 \\
Feeling Of Worthlessness & 43 & 22 \\
Insomnia & 39 & 37 \\
\hline
\end{tabular}

Table 2. Absolute and relative frequency distribution of spousal social support status in women under study $(\mathrm{n}=190)$

\begin{tabular}{lllll}
\hline Variable & Step & Status & Number & Percent \\
\hline & \multirow{3}{*}{ Before Menstruation } & Mild & 27 & 14.2 \\
& & Moderate & 139 & 73.2 \\
\cline { 2 - 5 } Social Support & Desirable & 24 & 12.6 \\
& \multirow{3}{*}{ During Menstruation } & Mild & 29 & 15.3 \\
& & Moderate & 130 & 68.4 \\
& & Desirable & 31 & 16.3 \\
\hline
\end{tabular}

\section{Discussion}

The aim of this study was to investigate the premenstrual syndrome, physical activity and spousal social support status among women in Isfahan city. Results indicated that based on ACOG diagnostic criteria, $79.5 \%$ of women suffered from PMS.

To compare this findings with other studies, we must consider several factor including: different definitions of PMS, cultural conditions, experiences, psychological expectations, the level of people's stress while explaining the symptoms, study methods, criteria, the questionnaires used, sampling methods, and the study population witch affect the prevalence of PMS symptoms (Pérez-López, Chedraui, Pérez-Roncero, López-Baena, \& Cuadros-López, 2009).

Based on ACOG diagnostic criteria, Hasan Zade and colleagues recorded the prevalence of premenstrual syndrome in teenagers as $83.1 \%$ (Bakhshani, 2012). Another study on the Iranian women working in factories reported that the prevalence of premenstrual syndrome in them was $67.7 \%$ and this prevalence in Iranian female university students was recorded as 98.2\% (Ramezani Tehrani, Hashemi, \& Allameh, 2012).

In different countries such as Egypt using International Classification of diseases (ICD-10), the prevalence of this syndrome was recorded as $89.6 \%$ (Bakr \& Ez-Elarab, 2010) and in Pakistan as 51\% (Nisar, Zehra, Haider, Munir, \& Sohoo, 2008). The prevalence of this syndrome in Japanese high school girls was recorded as $64.6 \%$ (Telek et al., 2010).

In this study the most frequent physical symptoms were respectively abdominal pain, fatigue, weakness and 
lethargy, loss of energy, breast tenderness, headache, and muscle aches; and the most frequent psychological symptoms were respectively irritability, mood changes, and feeling restless which were approximately similar to the results of Petta's study on Brazilian women (Petta, Osis, de Pádua, Bahamondes, \& Makuch, 2010) and on Yemeni women (Akabat \& Al Harazi, 2012).

In the present study, the age of women had a significant relationship with the prevalence of PMS. There are contradictory results considering the relationship between age and the prevalence of PMS. In Silva and colleagues' study, being under the age of 30 had a positive and significant relationship with more severe symptoms of premenstrual syndrome (Silva, Gigante, Carret, \& Fassa, 2006).

It is claimed that the level of higher education is accompanied with the prevalence of PMS which may be related to the increase in the level of those people's understanding, and as a result they report the symptoms more frequently (Ramezani Tehrani et al., 2012). In the present study, there was no significant relationship between PMS symptoms and women's educational levels. These results were similar to Kiyanis' findings (Kiyani Asyabar et al., 2009) but were inconsistent with Silvas' study (Silva et al., 2006).

There was no significant relationship between PMS and women's jobs but the symptoms of premenstrual syndrome were seen more frequently in the women who worked and, as it was mentioned before, one of the reasons for the insignificancy can be attributed to the decrease in the sample size and also to the small number of the women working compared with the number of housewives. This finding was similar to Adiguzel study (Adiguzel, Taskin, \& Danaci, 2007) and were contrary to Silva study (Silva et al., 2006).

No significant relationship was observed between PMS symptoms and menstrual cycle pattern but the persons with the menstrual cycle intervals shorter than 35 days had reported fewer PMS symptoms than those who had menstrual cycle intervals longer than 35 days. Also, no statistically significant Relationship between PMS symptoms and bleeding days was reported. The results of this study were similar to the findings of previous study (Ramezani Tehrani et al., 2012) but were not consistent with Kiyani and colleagues' study and this suggests that those who have menstruation bleeding longer than 8 days and those whose cycle intervals are longer than 35 days will more probably experience more PMS symptoms (Kiyani Asyabar et al., 2009).

Desirable spousal social support in premenstrual and during the period were obtained in $12.6 \%$ and $16.3 \%$ respectively.

There is a significant positive relationship between the scores of spousal social support and men's education. Also more spousal social support in women was observed by increase in educational levels which is statistically going to be significant. Again one of the reasons for this insignificancy can be attributed to the small number of samples. In other studies, men with higher education provided more spousal social support to their wives (Rezaee et al., 2015).

There was a statistically significant relationship between spouses' jobs and spousal social support scores. The lowest level of support was seen in the jobless people and the highest level of support was observed in the employees. The consequence of higher education and social status of spouses was receiving more spousal social support from men. And employed women received more spousal social support than housewives but this relationship was not statistically significant and one of the reasons for this insignificancy can be the small number of women working compared to the number of housewives.

The highest score of spousal social support (being considerate towards wife during menstruation) was $85.3 \%$ and the lowest score of support (avoiding argument with wife during menstruation) was reported as $5.8 \%$.

A significant relationship was observed between the scores of spousal social support before and during menstruation, that is, an increase in the score of Support before menstruation was paralleled by an increase in the score of support during menstruation and of course the score of support during menstruation was higher than the score of support before menstruation.

The present study showed that an increase in the score of support was paralleled by a decrease in PMS symptoms but this relationship was not statistically significant. The results of this study were inconsistent with the findings of previous study (Haywood et al., 2007).

TO promote women's health in reproductive ages, men's participation; as a main factor emphasized by WHO; is possible through education. According to the findings of this study, providing suitable educational programs to promote men's participation and also paying more attention to the effects of men's attention on providing, maintaining, and promoting women's health in reproductive ages in pre-marriage counseling is suggested.

The present study had some limitations. The first is the small number of participants; the secend was data 
collection method as retrospective completion of questionnaires. Thus for better understanding of the relationship between spousal support and PMS status, it is suggested further studies by larger number of participants and in a prospective methods.

\section{Conclusion}

Consistent with previous studies in Iran, in present study revealed that a large number of women suffer from the PMS and are deprived of appropriate spousal social support. Holding educational intervention for couples in reproductive age about PMS and spousal social support in Health care centers are necessary.

\section{Acknowledgments}

The article is the product of an MA thesis accepted and sopported by University of Medical Sciences in Isfahan. I would like to acknowledge the upright staffs of Health Care Centers of Isfahan city and reputable pairs who contributed in the study.

\section{Competing Interests Statement}

The authors declare that there is no conflict of interests regarding the publication of this paper.

\section{References}

Adiguzel, H., Taskin, E. O., \& Danaci, A. E. (2007). The symptomatology and prevalence of symptoms of premenstrual syndrome in Manisa, Turkey. Turk Psikiyatri Dergisi, 18(3), 215.

Akabat, M. Y., \& Al Harazi, A. H. (2012). Menstrual disorders in female medical students in Thamar University (Vol. 7, p. 10).

Azimi, H., \& Sadeghi, T. (2013). The effect of aerobic and walking exercise on physical and psychological symptoms and pain of premenstrual syndrome. Iran Journal of Nursing, 25(80), 46-55.

Bakhshani, N., \& Hasanzadeh, Z. (2012). Comparison of food consumption adolescent students with signs and symptoms of premenstrual syndrome. Med J Mashad Univ Med Sci, 55(3), 151-157.

Bakr, I., \& Ez-Elarab, H. S. (2010). Prevalence of premenstrual syndrome and the effect of its severity on the quality of life among medical students. The Egyptian Journal of Community Medicine, 28(2), 19-30.

Balaha, M., Amr, M., Moghannum, M., \& Muhaida, N. (2010). The phenomenology of premenstrual syndrome in female medical students: A cross sectional study. Pan African Medical Journal, 5(1). http://dx.doi.org/10. 4314/pamj.v5i1.56194

Chantler, I., Mitchell, D., \& Fuller, A. (2009). Diclofenac potassium attenuates dysmenorrhea and restores exercise performance in women with primary dysmenorrhea. The Journal of Pain, 10(2), 191-200. http://dx.doi.org/10.1016/j.jpain.2008.08.006

Delara, M., Ghofranipour, F., Azadfallah, P., Tavafian, S. S., Kazemnejad, A., \& koushki, M. (2013). Development and Psychometric Assessment of premenstrual syndrome in Sabzevar city high school youth. J North Khorasan Univ Med Sci, 3(4), 55-62.

Direkvand-Moghadam, A., Sayehmiri, K., Delpisheh, A., \& Sattar, K. (2014). Epidemiology of Premenstrual Syndrome (PMS)-A Systematic Review and Meta-Analysis Study. Journal of Clinical \& Diagnostic Research, 8(2).

Freeman, E. W., Halberstadt, S. M., Rickels, K., Legler, J. M., Lin, H., \& Sammel, M. D. (2011). Core symptoms that discriminate premenstrual syndrome. Journal of Women's Health, 20(1), 29-35. http://dx.doi.org/10. 1089/jwh.2010.2161

Greene, M. E., Mehta, M., Pulerwitz, J., Wulf, D., Bankole, A., \& Singh, S. (2006). Involving men in reproductive health: Contributions to development. Millennium Project Washington, DC.

Haywood, A., Slade, P., \& King, H. (2007). Psychosocial associates of premenstrual symptoms and the moderating role of social support in a community sample. Journal of psychosomatic research, 62(1), 9-13. http://dx.doi.org/10.1016/j.jpsychores.2006.07.024

Hoga, L. A. K., Vulcano, M. A., Miranda, C. M., \& Manganiello, A. (2010). Male behavior in front of women with Premenstrual Syndrome: Narratives of women. Acta Paulista de Enfermagem, 23(3), 372-378. http://dx.doi.org/10.1590/S0103-21002010000300010

Kiyani Asyabar, A., Heidari, M., Mohammadi Tabar, S., \& Faghihzadeh, S. (2009). Prevalence, symptoms, signs and predisposing factors of premenstrualsyndrome in women. Daneshvar Med, 16(81), 45-54. 
Mazaheri, M. A., Rabiei, L., Masoudi, R., Hamidizadeh, S., Nooshabadi, M. R. R., \& Najimi, A. (2014). Understanding the factors affecting the postpartum depression in the mothers of Isfahan city. Journal of education and health promotion, 3.

Najafi-Sharjabad, F., Hejar Abdul Rahman, M. H., \& Yahya, S. Z. S. (2014). Spousal communication on family planning and perceived social support for contraceptive practices in a sample of Malaysian women. Iranian journal of nursing and midwifery research, 19 (7 Supp11), S19.

Nisar, N., Zehra, N., Haider, G., Munir, A. A., \& Sohoo, N. A. (2008). Frequency, intensity and impact of premenstrual syndrome in medical students. $J$ Coll Physicians Surg Pak, 18(8), 481-484.

Pérez-López, F. R., Chedraui, P., Pérez-Roncero, G., López-Baena, M. T., \& Cuadros-López, J. L. (2009). Premenstrual syndrome and premenstrual dysphoric disorder: symptoms and cluster influences. Open Psychiatry Journal, 3(47), 39-49. http://dx.doi.org/10.2174/1874354400903010039

Petta, C. A., Osis, M. J. D., de Pádua, K. S., Bahamondes, L., \& Makuch, M. Y. (2010). Premenstrual syndrome as reported by Brazilian women. International Journal of Gynecology \& Obstetrics, 108(1), 40-43. http://dx.doi.org/10.1016/j.ijgo.2009.07.041

Ramezani Tehrani, F., Hashemi, S., \& Allameh, M. (2012). Prevalence of premenstrual syndrome and some related factors of reproductive age. Ofoghe danesh, 18(3), 122-127.

Rezaee, H., Mahamed, F., \& Mazaheri, M. A. (2015). Does Spousal Support Can Decrease Women's Premenstrual Syndrome Symptoms? Global journal of health science, 8(5), 19. http://dx.doi.org/10.5539/ gjhs.v8n5p19

Samadi, Z., Taghian, F., \& Valiani, M. (2013). The effects of 8 weeks of regular aerobic exercise on the symptoms of premenstrual syndrome in non-athlete girls. Iranian journal of nursing and midwifery research, 18(1).

Shin, K. R., Ha, J. Y., Park, H. J., \& Heitkemper, M. (2009). The effect of hand acupuncture therapy and hand moxibustion therapy on premenstrual syndrome among Korean women. Western journal of nursing research, 31(2), 171-186. http://dx.doi.org/10.1177/0193945908323650

Silva, C. M. L. D., Gigante, D. P., Carret, M. L. V., \& Fassa, A. G. (2006). Population study of premenstrual syndrome. Revista de saúde pública, 40(1), 47-56. http://dx.doi.org/10.1590/S0034-89102006000100009

Telek, T., Gonda, X., Lazary, J., Benko, A., Pap, D., Vargha, A., \& Bagdy, G. (2010). The possible protective role of personality dimensions against premenstrual syndrome. Psychiatry research, 179(1), 81-85. http://dx.doi.org/10.1016/j.psychres.2009.02.014

Weisz, G., \& Knaapen, L. (2009). Diagnosing and treating premenstrual syndrome in five western nations. Social Science \& Medicine, 68(8), 1498-1505. http://dx.doi.org/10.1016/j.socscimed.2009.01.036

\section{Copyrights}

Copyright for this article is retained by the author(s), with first publication rights granted to the journal.

This is an open-access article distributed under the terms and conditions of the Creative Commons Attribution license (http://creativecommons.org/licenses/by/4.0/). 